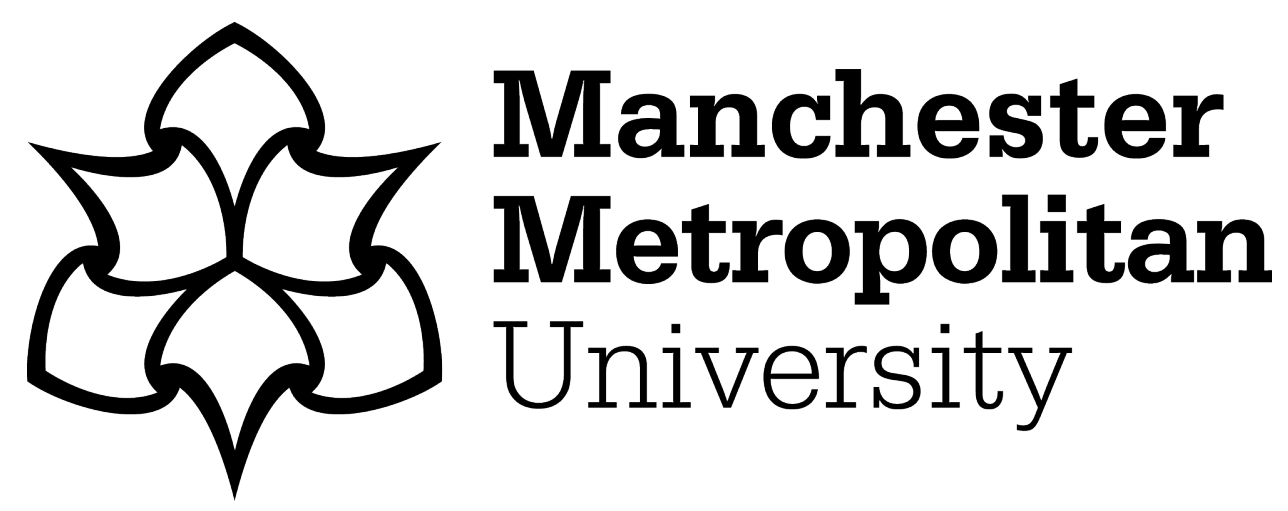

Sung, Anna, Leong, Kelvin and Cunningham, Stuart ORCID logoORCID: https://orcid.org/0000-0002-5348-7700 (2020) Emerging Technologies in Education for Sustainable Development. In: Partnerships for the Goals. Springer Nature. ISBN 978-3-319-71067-9

Downloaded from: https://e-space.mmu.ac.uk/625355/

Version: Accepted Version

Publisher: Springer Nature

DOI: https://doi.org/10.1007/978-3-319-71067-9_61-1

Please cite the published version 


\section{Emerging Technologies in Education for Sustainable Development}

\author{
Anna Sung ${ }^{1}$, Kelvin Leong ${ }^{1}$ and \\ Stuart Cunningham ${ }^{2}$ \\ ${ }^{1}$ Chester Business School, University of Chester, \\ Chester, UK \\ ${ }^{2}$ Department of Computing and Mathematics, \\ Manchester Metropolitan University, Manchester, \\ UK
}

\section{Definitions}

Education plays a key role in sustainable development in terms of changing behavior of people to achieve the sustainability development goals. On this, technology can be used to enhance education for sustainable development (ESD) through influencing learners' behavior and to evaluate such behavior change. In order to effectively apply technology to support ESD, a strong partnership between educators and technologists is needed in order to unlock the potential of both sides and to create synergies through specialization. Partnership with technologists benefits educators in several ways, such as speeding up innovation process in education, stimulating fresh teaching ideas, improving learners' experience, widening access to skills and resources, etc. Moreover, partnership opens the opportunity for both sides to share their knowledge, expertise, and experience of success with one another in a way that benefits all parties involved.

\section{Introduction}

According to Brundtland (1987) and Gladwin et al. (1995), the core of sustainable development is "to meet the needs of the present without compromising the ability of future generations to meet their own needs." We can also consider that today's behavior will affect whether the needs in future can be met or not. For example, when a resource is used up by humans because of overconsumption (i.e., behavior), the need of the resource will not able be met in the future. On the other hand, human's behavior can also be considered as the result of learning. Therefore, education plays a key role in sustainable development in terms of changing human's behavior.

This entry aims to review how technologies can be used to support education for sustainable development purposes. More specifically, we will focus on how and what technologies can be used to change human behavior to achieve sustainable development goals and how the changes can be evaluated.

This entry is organized as follows. Firstly, the background of education for sustainable development will be reviewed. Secondly, the concepts of persuasive design and gamification will be discussed, and the discussion will provide a direction on what are the related technologies in 
education for sustainable development. Thirdly, sense-related technologies and wearable technology are reviewed, and their contributions to sustainable development education will be discussed. Finally, we review what and how technologies can help to evaluate human behavior change.

\section{Education for Sustainable Development}

Sustainable development is every people's issue and is a complex topic that involves the interplay of three aspects: economy, environment, and society (Giddings et al. 2002) The key of education for sustainable development is not simply about receiving a certificate or getting a qualification; an ideal education for sustainable development should be able to make an unforgettable impact that changes a person's knowledge, skills, values, beliefs, attitudes, and behavior all in line with sustainable development goals.

In education, learning is a key component and is a process of a series of behavior. The process starts with the connection between the learner and the related content. A content could be delivered through various forms, such as a video, a lecture, a self-study program, a book, or any other. Moreover, the connection is also a stage for the learner to acquire new information, and the whole subsequent learning process builds upon on this stage.

In the age of the Internet and the Internet of Things (IoT), there are many ways to educate people, or in other words, there are many ways for people to learn. For example, on the online platform (www.edx.org), there were 2778 online course available as at 3 Sept 2019. In addition, there are many ways for people to learn new knowledge or skills from nontraditional informal platforms other than classrooms, such as watching videos on YouTube or Khan Academy.

However, a situation of today's education is that huge volume of data and information have been and are being generated, processed, transmitted, and recorded due to the fast development of various IoT devices. As per the figure from the Institute of Physics (http://www.physics.org/ thankphysics/internet/), the volume of data is huge to a point that "It would take around three million years to download all the information currently on the internet, assuming a download speed of 44 megabits per second." Moreover, the growing popularity of social media also has changed human's daily life and encouraged more data to be generated. For example, previous reports found that there were in average 95 million photos being uploaded per day on Instagram in 2016 (Woollaston 2016), more than 50 million businesses had Facebook pages, and more than 2.5 billion comments were made on these pages per month in 2015 (Chaykowski 2015).

There are many potential issues for information overload, such as it can decrease the human attention span. An example can be found in the music industry; according to Gauvin (2017), the average time that passed before the audience would hear the vocals on any radio song was $23 \mathrm{~s}$; and today the average intro is just $5 \mathrm{~s}$. Another effect is that the huge volume of data and information would encourage people to selectively obtain new information from daily life. On this, Hogarth (1987) suggested that selective perception may be the most influential action during the information acquisition stage. Therefore, a key challenge of learning is how to improve the connection between learner and corresponding teaching contents in order to help them to achieve the learning objectives.

In this entry, we discuss how technology can help to improve the connection between learner and the corresponding teaching contents. The contributions of technology can be summarized into two types. The first is technology influencing human behavior, and the second is evaluating behavior change by using technology.

\section{Technology Influencing Human Behavior}

We will review what and how technologies support learning in terms of affecting human behavior toward sustainable development goals. The review is based on the concepts of persuasive design. 


\section{Persuasive Design}

Persuasive design focuses on influencing human behavior through a product's or service's characteristics, and it has been applied in promoting sustainable development goals in a number of ways. For example, managing food waste is a mean to improve our environmental and economic sustainability; on this, Aydin et al. (2017) combined elements of behavior change and persuasive design theories and used personified icons to notify its users about the expiry conditions of the associated food items. Haller et al. (2017) applied persuasive approach to encourage sustainable change of users' behavior in energy consumption. Liu (2019) presented a project that aims to promote sustainable tourism through persuasive design.

Reeves and Nass (1996) present compelling results from experimental work, which suggest that human interactions with computers, and by extending other forms of technology, often mirror the dynamics of human-to-human interactions. Thus, they argue that human users view technologies in the same way as they would another person. As such, theories of social psychology, including social cognition and persuasion, are likely to be applicable in mediating successful technological interactions. Nkwo et al. (2018) designed and implemented a mobile persuasive system that motivated users to change their attitudes and behavior toward waste disposal and to care more for the environment. Hedemalm et al. (2017) investigated the use of a persuasive multiplayer game that provided bonuses and penalties to users based on their daily choices regarding transportation. Preliminary results from testers of the game indicated that using games may be successful in causing positive changes in user behavior.

More specifically explanation of persuasive design was provided in Fogg's Behavior Model (Fogg 2009). It described behavior as a product of three factors:

- Motivation (people have to be sufficiently motivated to change their behavior)

- Ability (the people must have ability to behave)
- Triggers (the people have to be triggered, or promoted, to behave)

Persuasive designs can incorporate both positive and negative approaches, typically by either offering some form of reward or punishment in provoking or responding to a user interaction. This principally aligns with the motivation aspect of Fogg's Model, although clearly triggers can be made more, or less, attractive, by making explicit the reward or punishment outcomes. Many examples of Fogg's Model in action can be found in computer games, especially those contemporary mobile games that offer in-game rewards and/or monetization mechanics, such as those employing loot boxes (Drummond and Sauer 2018) or "gacha" (Shibuya et al. 2015; Koeder and Tanaka 2017) style games.

In design of education for sustainable development, the above factors should be taken into considerations in order to help learners to achieve behavior change toward sustainable development goals. In practice, gamification is an effective way to implement persuasive design in education.

\section{Gamification}

Playing a game is a good way to learn (Golinkoff and Hirsh-Pasek 2006). Gamification in learning is an approach where gameplay elements are inserted in learning settings. The three key elements of Fogg Behavior Model (i.e., motivation, ability, and trigger) often play key roles in gamification design in order to enhance learner's engagement and happiness.

Previous studies have suggested that gamification is promising in terms of improving learning results and other factors related to the broader learning experience and process. This can be exemplified in the systematic review undertaken by Connolly et al. in 2012, which focused upon detailing empirical work evaluating the impact of serious games. Su and Cheng (2015) developed a context-aware mobile learning environment to influence science learning, achievement, and motivation. The feedback from students showed that they valued the learning activities made possible by the use of gamified 
learning approach. Vaibhav and Gupta (2014) found that if the learning platform is gamified, it does not only drastically increase the user enrolment but also increases user engagement throughout the course. Increased engagement was also found by Pourabdollahian et al. (2012); in their study, a serious game in manufacturing education was used. Moreover, gamification also makes learning become a unique and amusing experience. Tan et al. (2019) introduced gamification approach based on the online interactive quiz platform Kahoot in order to support foreign language learning. The findings indicated that the approach can benefit students in terms of inducing motivation and fostering and reinforcing learning.

Given sustainable development is a complex topic and involves people from different backgrounds; on this, gamification should be considered as a good approach to support education for sustainable development purposes. This is because previous studies have proved that gamification can be applied in many different applications for different types of user. For example, Ibanez et al. (2014) applied a gamification approach to teach computer science students to learn the $\mathrm{C}$ programming language. Moncada and Moncada (2014) reported the use of gamification to overcome the challenges of studying accounting. Ke and Grabowski (2017) indicated gameplaying was more effective in promoting maths performance, and cooperative game-playing was most effective for promoting positive maths attitudes regardless of students' individual differences. Robson (2019) introduced a gamified pedagogical exercise that students receive and lose points for various behavior and reflect on whether those behavior support or conflict with their desired brand image. Berger and Schrader (2016) suggested a gamification approach to encourage participants to change their actual nutritional behavior and convert good intentions into action.

In practice, gamification has been introduced to encourage behavior change in the sustainability development context. For example, Huber and Hilty (2015) discussed how gamification-based approaches may give users more autonomy in selecting goals and relating individual actions to social interactions, in addition, enabling the transition toward sustainable consumption patterns. Fraternali et al. (2015) presented the SmartH2O platform, which is a system for water demand management. Engagement was reinforced through a unique mix of in-app gamification techniques, digital educational games, and real board games, which provided a rich set of behavior change stimuli to all household members. Gatti et al. (2019) presented and evaluated a gamified teaching approach for sustainable development education based on an action learning approach. The results revealed that the surveyed students had a very high level of satisfaction with the game. Negruşa et al. (2015) discussed the relationship between gamification and sustainability and reported the successful stories of gamification applied in hospitality and tourism. Industry 4.0 , as a new industrial paradigm, points toward the creation of more sustainable processes. On this, Paravizo et al. (2018) concluded gamification mechanics can contribute to support manufacturing education on Industry 4.0, enabling innovation and sustainability.

The rapid development of technologies is becoming a driving force to promote gamification in education. In fact, technology-enabled gamification can be implemented in different ways. Previous examples include Cavus and Ibrahim (2009), who developed a game based on short message service (SMS) text messaging to teach English language words, and it achieved a transformation of the traditional classroom-based learning and teaching into anytime and anywhere education. De Freitas et al. (2010) combined the uses of virtual worlds, with text-based, voicebased, and a feeling of "presence" naturally to design gamified learning activities for college and lifelong learners in order to encourage learner empowerment through increased interactivity. Edwards et al. (2002) reported how to design game-playing lectures based on the use of interactive whiteboards that allowed teachers to monitor pupils' progress and "to identify weaknesses or misconceptions very early in the activity so that these can be rectified." Cózar-Gutiérrez and SáezLópez (2016) presented the use of video games in initial teacher training in social sciences; the 
findings indicated that game-based learning through immersive environments allowed learning that involves a higher level of activity and engagement of the students. Cerrato et al. (2017) reported the development of DILIGO as a tool for smart assessment of preschool children attitudes in terms of evaluating the children preference for a certain activity, giving information for orienting in school and work context. Grom et al. (2017) introduced a gamifying Peer Learning Assessment System (PeLe) that students could use to gain a new understanding of what assessment in higher education could look like. Based on a research study with 130 participants, the findings from the Bicen and Kocakoyun (2017) suggested that the Kahoot platform was the mostly preferred application by students and Android was the mostly preferred operating system in the mobile devices of the students. It is worth mentioning that the human is still the key factor in any form of gamification. As per Di Bitonto et al. (2014), when gamification was used in the simulation of clinical cases, the trainer interaction that is useful in order to keep the system up to date over time and to allow the definition of clinical cases tailored based on users' needs.

Moreover, among different types of technology, sense-related technologies are important in the design of education. This is because sensation plays a key role in influencing human behavior. Previous studies had found close relationships between human sense and behavior. For example, Courtis (2004) identified there were some colors that had positive effects on perception formation and investment allocations. Leong et al. (2019) found that users prefer to choose the financial data presented in cool colors in business management context. Salamé and Baddeley (1989) examined and proved the effects of different types of background music and sounds, such as unattended vocal, instrumental music, and instrumental music with unattended speech and with noise modulated in amplitude on phonological shortterm memory. Taylor et al. (2009) found that mindfulness training has an impact on cognition and affect specifically associated with voices and thereby beneficially alters relationship with voices. Hallam et al. (2002) studied the effects of music, perceived to be calming and relaxing, on performance in arithmetic and a memory task in children aged 10-12. The findings suggested the calming music led to better performance in both tasks when compared with a no-music control condition. Music perceived as arousing, aggressive, and unpleasant disrupted performance on the memory task and led to a lower level of reported altruistic behavior by the children. Ward et al. (2004) used ambient scent within retail environments to shape the emotional and behavioral responses. Guéguen and Petr (2006) found that a relaxing effect produced by a lavender scent increased the length of stay of customers and the amount of purchasing in restaurant. In a case study of the homeware store IKEA, Hultén (2012) suggested that visual and olfactory sensory cues had a positive impact on shoppers' touching behavior, purchase intentions, and total sale. Eriksson and Larsson (2011) found that a combination of sensory cues led to a change in customers' behavior and created approach behavior through awareness of products that otherwise could be missed.

In general, there are five senses in humans, including smell, sight, touch, taste, and hearing. These five senses are also the five ways that humans connect with their real-world surroundings and may be stimulated into cognitive and emotional responses (Cunningham and Weinel 2016). Sense-related technologies can stimulate these senses through creating digital user experience, and the created experience can encourage learners to change their behavior toward sustainable development goals. For example, instead of providing a text message, using multimedia platforms with $3 \mathrm{D}$ visual elements with sound and smell together can give learner a deep impression on why plastic is a problem for sea turtles and the ocean. This deep impression may also be more powerful in changing the learner's behavior in terms of consuming plastic. Further discussions on how sense-related technologies affect learning are provided as follows.

\section{Sense-Related Technologies and Learning}

In recent years, many sense-related technologies have been proposed and developed. Virtual reality 
(VR) is one of the most emerging sense-related technology topics. As per Rogers (2019), VR market volume is expected to reach USD 98.4 million sales by 2023, generating an installed base of 168 million units with a worldwide population penetration of $2 \%$. In simplicity, VR refers to using technology to create environments designed expressly for human interaction and doing so by visually, and sometimes auditorily as well, separating the user from their real-world environment. VR can be used to enhance student learning and engagement in classroom. One of the key features is that VR allows us to create any environment, real, or imagined, for simulated interactions.

According to previous studies, VR can stimulate human experience and then change their behavior. For example, McComas et al. (2002) designed a course for children to learn safe street crossing within the virtual environment. The results suggested that suburban school children's street crossing behavior was improved, and the good practice was transferrable to their realworld behavior. Bordnick et al. (2012) reported a VR-based treatment approach for smoking cessation; the result suggested that smoking rates and craving for nicotine were significantly lower at the end of treatment. Also, self-confidence and coping skills were significantly higher, and number of cigarettes smoked was significantly lower for the participants after the treatment. Given VR can help learners to change their behavior, it can be used as a key element in education program in order to help learners to achieve behavior change toward sustainable development goals.

The key advantages of VR include creating learning experience that is impossible to do it easily in real world, helping learners to learn conceptual ideas, improving collaborating learning, and supporting different educational ideas. The following are related discussion points about why these advantages are important to sustainable development education.

\section{On Creating a Learning Experience That Is} Impossible to Do It Easily in Real World Some previous examples include, as per Ausburn and Ausburn (2004), VR is basically a way of simulating or replicating an environment and giving the user a sense of being there, taking control, and personally interacting with that environment with his/her own body. Mintz et al. (2001) created a dynamic 3D model of the solar system that the learner could enter a virtual model of the physical world, journey through it, zoom in or out as he or she wished, change his or her view point and perspective. Asai et al. (2010) developed a lunar surface navigation system on virtual environment, which facilitated collaboration between children and parents with active learning behavior. Boudreaux et al. (2009) presented a virtual reality volcano activity learning environment that immersed students in a scientifically accurate simulation of volcanic systems. In some situations, resource is a factor that limits students' learning opportunities. For example, as reported by Tüysüz (2010), due to lack of laboratories at schools or insufficient instruments in laboratories, hands-on experiments were rarely performed in state schools in Turkey. Therefore, a VR laboratory was developed for students to conduct experiments virtually.

Given many sustainable development topics are related to the situations that are difficult to experience in person, such as the impacts of global warming and pollution on biodiversity, the use of VR can help learners to experience the impacts effectively and impressively without the needs of doing field trips or being put in situations where there are unreasonable risks to their health and safety.

\section{On Helping Learners to Better Absorb Conceptual Ideas}

Some previous applications include Mantovani et al. (2003) applied immersive 3D environments for training psychiatrists and psychologists in the treatment of mental disorders. In the case of Pasqualotti and Freitas (2002), VR was applied to support teaching and learning mathematics, the students benefitted from the VR environment because VR enabled the students to navigate and interact with virtual objects, moving around and visualizing the virtual objects from different angles. Pivik et al. (2002) reported a desktop VR program for teaching children about the 
accessibility and attitudinal barriers encountered by their peers with mobility impairments. The results indicated the program was effective for increasing children's knowledge of accessibility barriers. Bogusevschi et al. (2019) developed a 3D immersive computer-based physics educational application that taught learners about the water cycle in nature and precipitation formation concepts through VR and experimental virtual laboratory simulations.

Given many sustainable development topics are related to conceptual ideas, such as the benefits of fair trade, learning materials could be designed with VR to enable learners to interact with different scenarios; thus, learners can "see" different outcomes and can better understand and absorb conceptual ideas.

\section{On Improving Collaborative Learning}

Previous experiences include Monahan et al. (2008) presented a collaborative learning environment "CLEV-R." The web-based system CLEV-R used VR and multimedia assets and provided communication tools to support collaboration among online students. Collaborative VR learning experiences can be successfully integrated into existing curricula to support collaborative learning. Beer et al. (2005) reported an online Internet school for occupational therapists that encouraged students from four European countries to work collaboratively through problembased learning by interacting with each other in a virtual semi-immersive environment.

Given sustainable development is a complex topic and involves stakeholders from a multitude of different backgrounds, using VR can facilitate learners from different circumstances to share their insights and create new knowledge.

\section{On Supporting Different Education Ideas}

For example, Zarzuela et al. (2013) reported a VR serious game that allowed the students to increase the knowledge about the city of Valladolid in Spain. The game created a virtual environment set within the main square and some of the historic buildings in the downtown region. It further took an advantage of the characteristic tiled floor of the town hall square to represent a game board and designed hidden questions behind the different tiled floors for better engagement. On the other hand, role-play is a useful tool on teaching how best to communicate and react in difficult scenarios. On this, Drewett et al. (2019) reported the use of immersive VR consultation, which involved different ethical scenarios, such as abuse, to train medical general practitioners and trainees on how to recognize and manage child protection issues. Moreover, Arrowsmith et al. (2005) developed a virtual field trip to encompass field observation for several geographic scales. Therefore, students were able to obtain a general overview of the area into which they would be working and obtain background information in an interactive threedimensional model that enabled students to maximize their experience before undertaking fieldwork in situ. Furthermore, as per the feedback from the students in the study of Davies and Dalgarno (2009), the advantages of VR learning included opportunities for students to revisit the virtual scene as many times as they wanted, at a time convenient to them, which gave it advantages over a real investigation task if they were to be provided with only one or the other option.

Given VR can be used to support different educational ideas, leaners can earn different experiences from different ideas, and these ideas can help learners to gain deeper understanding on the topics and be able to apply their learnt knowledge and skills. Most importantly, according to the previous experiences, VR can lead to better learning results. For example, Buchanan (2004) reported upon the use of virtual reality-based technology (VRBT) for the instruction of dental students in preclinical restorative procedures. The evaluation results suggested that students learned faster, arrived at the same level of performance, accomplished more practice procedures per hour, and requested more evaluations per procedure or per hour than in other traditional laboratories. The findings from Bailenson et al. (2008) suggested that participants learned better in VR than in a video learning condition in terms of both selfreport measures and objective performance measures. In the study of Parong and Mayer (2018), the findings suggested that students' motivation, interest, and engagement ratings were higher 
when they learned in immersive VR rather than well-structured PowerPoint slideshow.

Other than VR, there are other sense-related technologies that can influence human sensation and affect human experience. For example, augmented reality (AR) and mixed reality (MR) similar technologies, which form part of the wider definition of extended reality (XR) environments. AR is an interactive experience of a real-world environment where the objects that reside in the real-world are enhanced by computer-generated perceptual information. MR is the merging of real and virtual worlds to produce new environments and visualizations where physical and digital objects coexist and interact in real time. In brief, the development of VR, AR, or MR is very much benefited from the enabling wearable technology.

\section{Wearable Technology}

Wearable technology refers to any electronic devices that can be worn as accessories, incorporated in clothing and accessories, implanted in the user's body, or even tattooed on a human's skin. Basically, wearable technology is the physical platform to deliver digital experiences to learners and is the base of sense-related technology. Use of wearable technology in education has been proved effective according to previous cases. For example, Beard et al. (2016) reported the use of wearable video technology to support surgical education and led to the training being faster and better by overcoming the challenge of traditional "see one, do one, teach one" practice. Kerner and Goodyear (2017) explored the impact of a wearable health and fitness device, such as Fitbit, on adolescents' motivation for physical activity, and their related perceptions of these devices for health promotion. Moshtaghi et al. (2015) reviewed the use of Google Glass to solve communication and surgical education challenges in the operating room. Luthra et al. (2019) studied the use of wearable technology, such as "connected" glasses with a camera to support a series of simulated learning events in medical general practice (GP). The approach enabled trainees and patient actors to be observed by the trainers from a distant site in real time. Iqbal et al. (2016) compared the use of body sensors and head-mounted displays in medicine. The conclusion suggested that body sensors were found to have excellent functionality in aiding patient posture and rehabilitation, while head-mounted displays could provide information to surgeons while maintaining sterility during operative procedures (Science, Technology, Engineering and Mathematics) teaching and learning. The results showed that the approach increased students' knowledge of circuitry and engineering design, as well as their self-efficacy with wearable technologies and producing e-textile products.

Previous cases, including the abovementioned examples, provide cues on ways in which sustainable development education could be improved by using wearable technology, such as the use of Google Glass or similar visual overlay devices to visualize global economy relationships, the use of wearable devices to remind the consumption behavior, etc.

In fact, previous studies indicated that applications of wearable technology can lead to changes in behavior. According to the study from Jakicic et al. (2016), the addition of a wearable technology device to a standard behavioral intervention resulted in weight loss over 24 months. Very often, habitual behavior is hard to change because of lack of self-monitoring skills, while a potential contribution of wearable technology is the capacity to provide live feedback. Live feedback can be used to disrupt bad habits in interventions. Stephenson et al. (2017) used computer, mobile, and wearable technologies as interventions to facilitate a reduction in sedentary behavior. The results suggested effectiveness appeared most prominent in the short-term.

It is also worth mentioning that the development of related technologies is not complex and can be affordable. Markvicka et al. (2018) reported a systematic guide to a low-cost (less than USD 10 per student) outreach workshop on wearable electronics for middle school students. Therefore, the promotion of sustainable education in developing countries is possible through using low-cost equipments. 


\section{Evaluating Behavior Change by Using Technology}

Evaluation is an important part in education, and it reports upon the outcomes from the education process. On this, data analytics had been used in various applications in education. Thomas and Galambos (2004) used regression and decision tree analysis with the CHAID algorithm to analyze student-opinion data in order to investigate how students' characteristics and experience affected satisfaction. Quadri and Kalyankar (2010) presented the work of using data mining in predicting the drop out features of students. Delen (2011) developed analytical models to predict freshmen student attrition with an $81 \%$ overall prediction accuracy on the holdout sample. Siraj and Abdoulha (2009) applied data mining to investigate enrolment data in order to identify which part of the processes could be enhanced. Chen et al. (2014) conducted a text analytics with focus on students' informal conversations on Twitter posts in order to understand issues and problems in their educational experiences. These findings shed light onto their educational experiences-opinions, feelings, and concerns about the learning process. Wolff et al. (2013) developed predictive models to analyze historic virtual learning environment (VLE) activity data combined with other data sources. The results indicated that this approach could predict student failure by looking for changes in user's activity in the VLE, when compared against their own previous behavior.

Moreover, previous studies found that introducing data analytics could lead to better education results. For example, Cortez and Silva (2008) reviewed the use of four data mining techniques (i.e., decision trees, random forest, neural networks, and support vector machines) to predict secondary school student performance, and the results showed that a good predictive accuracy could be achieved, although it is worth noting that prediction outcomes from approaches such as neural networks are often not explainable, which may be of value in educational contexts. Minaei-Bidgoli et al. (2003) presented an approach to predict students' final grade based on features extracted from logged data in an education web-based system. The findings suggested that the method could be of considerable usefulness in identifying students at risk early, especially in very large classes, and allowed the instructor to provide appropriate advice in a timely manner. He (2013) suggested a combination of data mining and text mining techniques for a large amount of online learning data, and the approach could yield considerable insights and reveal valuable patterns in students' learning behavior.

Moreover, given the key purpose of education for sustainable development is to help learners to achieve behavior change toward sustainable development goals, therefore, evaluating human behavior change after the education is essential or otherwise the impacts of the education will be unknown. On this, the development of data analytics can help to better understand human behavior change. For example, Bahari and Elayidom (2015) proposed a data mining model to predict the behavior of customers to enhance the decision-making processes for retaining valued customers. Leong et al. (2008) introduced a Space-Time-Event Model for investigating criminal behavior over time and space. Rong et al. (2012) proposed a data mining technique to study tourism data, and the empirical results were considered as useful in helping tourism managers to define new target customers and to plan more effective marketing strategies. Lotfi et al. (2012) provided a data mining solution for supporting independent living of the elderly by means of equipping their homes with a simple sensor network to monitor their behavior. Foell et al. (2013) developed an approach that used travel histories collected from automated fare collection system (AFC) to extract features of personal transport usage and study their predictive power to forecast whether people access public transport services on a future day or not. Khedr and Yaseen (2017) suggested a data mining model based on sentiment analysis of financial news and historical stock market prices to predict stock market trends and achieved prediction accuracy results ranging from $72.73 \%$ to 
$86.21 \%$. Ghani and Fano (2002) used text learning techniques to the descriptions obtained from websites of retailers and found the approach could successfully create useful profiles of individual customers, groups of customers, or entire retail stores. Given previous examples have proved the promise of big data and data analytics as a way to understand human behavior change, data analytics can also be used to evaluate the impacts of sustainable development education, for example, by using spatial clustering techniques to determine if plastic consumption over an area disappeared or simply displaced to another location.

\section{The Importance of Partnership Relationship Between Educators and Technologists}

As mentioned in previous examples, the fastgrowing development of technologies creates many new opportunities in Education for Sustainable Development (ESD). However, a strong partnership between educators and technologists is needed in order to unlock the potential for both sides and to create synergies through specialization. Partnership with technologists benefits educators in several ways, such as speeding up innovation process in education, stimulating fresh teaching ideas, improving learners' experience, widening access to skills and resources, etc. In fact, such partnership challenges people to think, articulate, and receive clarity about their competencies. It serves as a mirror that gives each side (i.e., educators and technologists) a glimpse of their strengths and weaknesses. Moreover, partnership opens the opportunity for both sides to share their knowledge, expertise, and experience of success with one another in a way that benefits all parties involved. Furthermore, given both sustainable development and application of technology are quite complex by nature, working together can help both sides to focus on their own strengths without distraction.

\section{References}

Arrowsmith C, Counihan A, McGreevy D (2005) Development of a multi-scaled virtual field trip for the teaching and learning of geospatial science. Int $\mathrm{J}$ Educ Dev ICT 1(3):42-56

Asai K, Sugimoto Y, Billinghurst M (2010) Exhibition of lunar surface navigation system facilitating collaboration between children and parents in science museum. In: Proceedings of the 9th ACM SIGGRAPH conference on virtual-reality continuum and its applications in industry. ACM, pp 119-124

Ausburn LJ, Ausburn FB (2004) Desktop virtual reality: a powerful new technology for teaching and research in industrial teacher education. J Ind Teach Educ 41(4):1-16

Aydin A, Micallef A, Lovelace S, Li X, Cheung V, Girouard A (2017) Save the kiwi: encouraging better food management through behaviour change and persuasive design theories in a mobile app. In: Proceedings of the 2017 CHI conference extended abstracts on human factors in computing systems. ACM, pp 2366-2372

Bahari TF, Elayidom MS (2015) An efficient CRM-data mining framework for the prediction of customer behaviour. Proc Comput Sci 46:725-731

Bailenson J, Patel K, Nielsen A, Bajscy R, Jung SH, Kurillo G (2008) The effect of interactivity on learning physical actions in virtual reality. Media Psychol 11(3):354-376

Beard HR, Marquez-Lara AJ, Hamid KS (2016) Using wearable video technology to build a point-of-view surgical education library. JAMA Surg 151(8):771-772

Beer M, Slack F, Armitt G (2005) Collaboration and teamwork: immersion and presence in an online learning environment. Inf Syst Front 7(1):27-37

Berger V, Schrader U (2016) Fostering sustainable nutrition behavior through gamification. Sustainability 8(1):67

Bicen H, Kocakoyun S (2017) Determination of university students' most preferred mobile application for gamification. World J Educ Technol 9(1):18-23

Bogusevschi D, Muntean C, Muntean GM (2019) Teaching and learning physics using $3 \mathrm{D}$ virtual learning environment: a case study of combined virtual reality and virtual Laboratory in Secondary School. In: Society for Information Technology \& teacher education international conference. Association for the Advancement of Computing in Education (AACE), pp 467-474

Bordnick PS, Traylor AC, Carter BL, Graap KM (2012) A feasibility study of virtual reality-based coping skills training for nicotine dependence. Res Soc Work Pract 22(3):293-300

Boudreaux H, Bible P, Cruz-Neira C, Parham T, Cervato C, Gallus W, Stelling P (2009) V-volcano: addressing students' misconceptions in earth sciences learning through virtual reality simulations. In: International symposium on visual computing. Springer, Berlin/Heidelberg, pp 1009-1018

Brundtland GH (1987) Report of the world commission on environment and development: our common future. 
United Nations. https://sustainabledevelopment.un. org/content/documents/5987our-common-future.pdf. Accessed 10 Sep 2019

Buchanan JA (2004) Experience with virtual reality-based technology in teaching restorative dental procedures. J Dent Educ 68(12):1258-1265

Cavus N, Ibrahim D (2009) M-learning: an experiment in using SMS to support learning new English language words. Br J Educ Technol 40(1):78-91

Cerrato A, Ferrara F, Ponticorvo M, Sica LS, Di Ferdinando A, Miglino O (2017) DILIGO assessment tool: a smart and gamified approach for preschool children assessment. In: International conference on smart education and smart E-learning. Springer, Cham, pp 235-244

Chaykowski K (2015) Number of Facebook business pages climbs to 50 million with new messaging tools. Forbes. https://www.forbes.com/sites/kathleenchayko wski/2015/12/08/facebook-business-pages-climb-to-5 0-million-with-new-messaging-tools/\#10dd26bc1c2c. Accessed 13 Aug 2019

Chen X, Vorvoreanu M, Madhavan K (2014) Mining social media data for understanding students' learning experiences. IEEE Trans Learn Technol 7(3): 246-259

Connolly TM, Boyle EA, MacArthur E, Hainey T, Boyle JM (2012) A systematic literature review of empirical evidence on computer games and serious games. Comput Educ 59(2):661-686

Cortez P, Silva AMG (2008) Using data mining to predict secondary school student performance. Available via Research Gate. https://www.researchgate.net/profile/ Paulo_Cortez3/publication/228780408_Using_data mining_to_predict_secondary_school_student_perfor mance/links/0fcfd510a4efaa10b0000000/Using-datamining-to-predict-secondary-school-student-perform ance.pdf. Accessed 18 Aug 2019

Courtis J (2004) Colour as visual rhetoric in financial reporting. Account Forum 28(3):265-281

Cózar-Gutiérrez R, Sáez-López JM (2016) Game-based learning and gamification in initial teacher training in the social sciences: an experiment with MinecraftEdu. Int J Educ Technol High Educ 13(1):2

Cunningham S, Weinel J (2016) The sound of the smell (and taste) of my shoes too: mapping the senses using emotion as a medium. In: Proceedings of the audio mostly. ACM, pp 28-33

Davies A, Dalgarno B (2009) Learning fire investigation the clean way: the virtual experience. Australas J Educ Technol 25(1):1-13

De Freitas S, Rebolledo-Mendez G, Liarokapis F, Magoulas G, Poulovassilis A (2010) Learning as immersive experiences: using the four-dimensional framework for designing and evaluating immersive learning experiences in a virtual world. Br $\mathrm{J}$ Educ Technol 41(1):69-85

Delen D (2011) Predicting student attrition with data mining methods. J Coll Stud Retent Res Theory Pract 13(1):17-35
Di Bitonto P, Corriero N, Pesare E, Rossano V, Roselli $\mathrm{T}$ (2014) Training and learning in e-health using the gamification approach: the trainer interaction. In: International conference on universal access in humancomputer interaction. Springer, Cham, pp 228-237

Drewett O, Hann G, Gillies MFP, Sher C, Delacroix S, Pan X, Fertleman CR (2019) A discussion of the use of virtual reality for training healthcare practitioners to recognise child protection issues. Front Public Health $7: 255$

Drummond A, Sauer JD (2018) Video game loot boxes are psychologically akin to gambling. Nat Hum Behav 2(8):530

Edwards JA, Hartnell M, Martin R (2002) Interactive whiteboards: some lessons from the classroom. Micromath 18:30-33

Eriksson E, Larsson N (2011) A multi-sensory brandexperience: sensorial interplay and its impact on consumers' touch behaviour. Thesis, Linnaeus University

Foell S, Kortuem G, Rawassizadeh R, Phithakkitnukoon S, Veloso M, Bento C (2013) Mining temporal patterns of transport behaviour for predicting future transport usage. In: Proceedings of the 2013 ACM conference on pervasive and ubiquitous computing adjunct publication. ACM, pp 1239-1248

Fogg BJ (2009) A behavior model for persuasive design. In: Proceedings of the 4th international conference on persuasive technology. ACM, p 40

Fraternali P, Baroffio G, Pasini C, Galli L, Micheel I, Novak J, Rizzoli A (2015) Integrating real and digital games with data analytics for water consumption behavioral change: a demo. In: Proceedings of the 8th international conference on utility and cloud computing. IEEE Press, pp 408-409

Gatti L, Ulrich M, Seele P (2019) Education for sustainable development through business simulation games: an exploratory study of sustainability gamification and its effects on students' learning outcomes. J Clean Prod 207:667-678

Gauvin HL (2017) Drawing listener attention in popular music: testing five musical features arising from the theory of attention economy. Music Sci 22(2):291-304

Ghani R, Fano AE (2002) Using text mining to infer semantic attributes for retail data mining. In: 2002 IEEE international conference on data mining, 2002. Proceedings. IEEE, pp 195-202

Giddings B, Hopwood B, O'brien G (2002) Environment, economy and society: fitting them together into sustainable development. Sustain Dev 10(4):187-196

Gladwin TN, Kennelly JJ, Krause TS (1995) Shifting paradigms for sustainable development: implications for management theory and research. Acad Manag Rev 20(4):874-907

Golinkoff DGSRM, Hirsh-Pasek K (2006) Play= learning: how play motivates and enhances children's cognitive and social-emotional growth. Oxford University Press, New York

Grom A, Hansen G, Stoica G (2017) Gamifying experiences using a peer learning assessment system: 
combining two separate research traditions to promote student learning (poster and interactive session). In: 16th international conference on entertainment computing (ICEC), Tsukuba City, Sep 2017, pp 507-509

Guéguen N, Petr C (2006) Odors and consumer behavior in a restaurant. Int J Hosp Manag 25(2):335-339

Hallam S, Price J, Katsarou G (2002) The effects of background music on primary school pupils' task performance. Educ Stud 28(2):111-122

Haller H, Nguyen VB, Debizet G, Laurillau Y, Coutaz J, Calvary G (2017) Energy consumption in smarthome: persuasive interaction respecting user's values. In: 2017 9th IEEE international conference on intelligent data acquisition and advanced computing systems: technology and applications (IDAACS), vol 2. IEEE, pp 804-809

He W (2013) Examining students' online interaction in a live video streaming environment using data mining and text mining. Comput Hum Behav 29(1): 90-102

Hedemalm E, Hallberg J, Kor AL, Andersson K, Pattinson C (2017) Promoting green transportation via persuasive games. In: International conference on sustainable, ecological engineering design for Society (SEEDS), Leeds, 13-14 Sep 2017

Hogarth RM (1987) Judgement and choice: the psychology of decision, 2nd edn. Wiley, New York

Huber MZ, Hilty LM (2015) Gamification and sustainable consumption: overcoming the limitations of persuasive technologies. In: ICT innovations for sustainability. Springer, Cham, pp 367-385

Hultén B (2012) Sensory cues and shoppers' touching behaviour: the case of IKEA. Int $\mathrm{J}$ Retail Distrib Manag 40(4):273-289

Ibanez MB, Di-Serio A, Delgado-Kloos C (2014) Gamification for engaging computer science students in learning activities: a case study. IEEE Trans Learn Technol 7(3):291-301

Iqbal MH, Aydin A, Brunckhorst O, Dasgupta P, Ahmed $\mathrm{K}$ (2016) A review of wearable technology in medicine. J R Soc Med 109(10):372-380

Jakicic JM, Davis KK, Rogers RJ, King WC, Marcus MD, Helsel D, Rickman AD, Wahed AS, Belle SH (2016) Effect of wearable technology combined with a lifestyle intervention on long-term weight loss: the IDEA randomized clinical trial. JAMA 316(11): 1161-1171

Ke F, Grabowski B (2017) Gameplaying for maths learning: cooperative or not? $\mathrm{Br} \mathrm{J}$ Educ Technol 38(2):249-259

Kerner C, Goodyear VA (2017) Does wearable technology affect adolescents' motivation to be physically active? In: Niven K, Lewis S, Kagan C (eds) Making a difference with psychology. Richard Benjamin Trust, London, pp 107-115

Khedr AE, Yaseen N (2017) Predicting stock market behavior using data mining technique and news sentiment analysis. Int J Intell Syst Appl 9(7):22
Koeder MJ, Tanaka E (2017) Game of chance elements in free-to-play mobile games. A freemium business model monetization tool in need of self-regulation? In: 28th European regional conference of the international telecommunications society (ITS): competition and regulation in the information age, Passau, 30 July-2 Aug 2017

Leong K, Chan S, Ng V, Shiu S (2008) Introduction of STEM: space-time-event model for crime pattern analysis. Asian J Inf Technol 7(12):516-523

Leong K, Sung A, Williams T, Andoniou C, Sun F (2019) The importance of colour on the communication of financial data in management. J Work Appl Manag 11(1):92-100

Liu Z (2019) Sustainability by design: how to promote sustainable tourism behavior through persuasive design? Doctoral dissertation, University of Cincinnati

Lotfi A, Langensiepen C, Mahmoud SM, Akhlaghinia MJ (2012) Smart homes for the elderly dementia sufferers: identification and prediction of abnormal behaviour. J Ambient Intell Humaniz Comput 3(3):205-218

Luthra P, Brown J, Henshaw K (2019) OP11 wearable technology and simulation to support learning. Is it the way forward? A pilot study in primary care with healthcare professionals across the north west. BMJ Simul Technol Enhanc Learn 5:A7-A8

Mantovani F, Castelnuovo G, Gaggioli A, Riva G (2003) Virtual reality training for health-care professionals. CyberPsychol Behav 6(4):389-395

Markvicka E, Rich S, Liao J, Zaini H, Majidi C (2018) Low-cost wearable human-computer interface with conductive fabric for STEAM education. In: 2018 IEEE integrated STEM education conference (ISEC). IEEE, pp 161-166

McComas J, MacKay M, Pivik J (2002) Effectiveness of virtual reality for teaching pedestrian safety. CyberPsychol Behav 5(3):185-190

Minaei-Bidgoli B, Kashy DA, Kortemeyer G, Punch WF (2003) Predicting student performance: an application of data mining methods with an educational web-based system. In: 33rd annual frontiers in education, 2003, FIE 2003, vol 1. IEEE, pp T2A-T13A

Mintz R, Litvak S, Yair Y (2001) 3D-virtual reality in science education: an implication for astronomy teaching. J Comput Math Sci Teach 20(3):293-305

Monahan T, McArdle G, Bertolotto M (2008) Virtual reality for collaborative e-learning. Comput Educ 50(4):1339-1353

Moncada SM, Moncada TP (2014) Gamification of learning in accounting education. J High Educ Theory Pract 14(3):9

Moshtaghi O, Kelley KS, Armstrong WB, Ghavami Y, Gu J, Djalilian HR (2015) Using Google glass to solve communication and surgical education challenges in the operating room. Laryngoscope 125(10): 2295-2297

Negrușa A, Toader V, Sofică A, Tutunea M, Rus $R$ (2015) Exploring gamification techniques and 
applications for sustainable tourism. Sustainability 7(8):11160-11189

Nkwo M, Orji R, Ugah J (2018) Mobile persuasion: promoting clean and sustainable environment. In: Proceedings of the second African conference for human computer interaction: thriving communities. ACM, p 45

Paravizo E, Chaim OC, Braatz D, Muschard B, Rozenfeld $\mathrm{H}$ (2018) Exploring gamification to support manufacturing education on industry 4.0 as an enabler for innovation and sustainability. Proc Manuf 21: 438-445

Parong J, Mayer RE (2018) Learning science in immersive virtual reality. J Educ Psychol 110(6):785

Pasqualotti A, Freitas CMDS (2002) MAT3D: a virtual reality modeling language environment for the teaching and learning of mathematics. CyberPsychol Behav 5(5):409-422

Pivik J, McComas J, MaCfarlane I, Laflamme M (2002) Using virtual reality to teach disability awareness. J Educ Comput Res 26(2):203-218

Pourabdollahian B, Taisch M, Kerga E (2012) Serious games in manufacturing education: evaluation of learners' engagement. Proc Comput Sci 15:256-265

Quadri MM, Kalyankar NV (2010) Drop out feature of student data for academic performance using decision tree techniques. Global J Comput Sci Technol 19(2): 2-5

Reeves B, Nass CI (1996) The media equation: how people treat computers, television, and new media like real people and places. Cambridge University Press, Cambridge

Robson K (2019) Motivating professional student behavior through a gamified personal branding assignment. J Mark Educ 41:154. https://doi.org/10.1177/0273475 318823847

Rogers S (2019) 2019: the year virtual reality gets real. Forbes. Available via https://www.forbes.com/sites/ solrogers/2019/06/21/2019-the-year-virtual-reality-getsreal/\#32b1a7bd6ba9. Accessed 21 Aug 2019

Rong J, Vu HQ, Law R, Li G (2012) A behavioral analysis of web sharers and browsers in Hong Kong using targeted association rule mining. Tour Manag 33(4):731-740

Salamé P, Baddeley A (1989) Effects of background music on phonological short-term memory. Q J Exp Psychol 41(1): 107-122

Shibuya A, Teramoto M, Shoun A (2015) Systematic analysis of in-game purchases and social features of Mobile social games in Japan. In: DiGRA conference, 2015
Siraj F, Abdoulha MA (2009) Uncovering hidden information within university's student enrollment data using data mining. In: 2009 third Asia international conference on modelling \& simulation. IEEE, pp 413-418

Stephenson A, McDonough SM, Murphy MH, Nugent CD, Mair JL (2017) Using computer, mobile and wearable technology enhanced interventions to reduce sedentary behaviour: a systematic review and metaanalysis. Int J Behav Nutr Phys Act 14(1):105

$\mathrm{Su} \mathrm{CH}$, Cheng $\mathrm{CH}$ (2015) A mobile gamification learning system for improving the learning motivation and achievements. J Comput Assist Learn 31(3): 268-286

Tan DAL, Lee BC, Ganapathy M, Kasuma SAA (2019) Language learning in the 21st century: Malaysian ESL students' perceptions of Kahoot! Int J Virtual Pers Learn Environ 9(2):55-71

Taylor KN, Harper S, Chadwick P (2009) Impact of mindfulness on cognition and affect in voice hearing: evidence from two case studies. Behav Cogn Psychother 37(4):397-402

Thomas EH, Galambos N (2004) What satisfies students? Mining student-opinion data with regression and decision tree analysis. Res High Educ 45(3):251-269

Tüysüz C (2010) The effect of the virtual laboratory on students' achievement and attitude in chemistry. Int Online J Educ Sci 2(1):37-53

Vaibhav A, Gupta P (2014) Gamification of MOOCs for increasing user engagement. In: 2014 IEEE international conference on MOOC, innovation and technology in education (MITE). IEEE, pp 290-295

Ward P, Davies B, Kooijman D (2004) Ambient smell and the retail environment: relating olfaction research to consumer behavior. J Bus Manag 9(3):289-302

Wolff A, Zdrahal Z, Nikolov A, Pantucek M (2013) Improving retention: predicting at-risk students by analysing clicking behaviour in a virtual learning environment. In: Proceedings of the third international conference on learning analytics and knowledge. ACM, pp 145-149

Woollaston V (2016) Instagram now has half a billion users. Wired. https://www.wired.co.uk/article/instag ram-doubles-to-half-billion-users. Accessed 10 Aug 2019

Zarzuela MM, Pernas FJD, Calzón SM, Ortega DG, Rodríguez MA (2013) Educational tourism through a virtual reality platform. Proc Comput Sci 25: 382-388 